\title{
Relation of the administrative leadership with administrative creativity level of the employees in youth and sports directorate, Elmsila state, Algiers \\ *dr/ boukhors ramdane aloun souad \\ ****** layadi abd elhakim hadibi ismail
}

Abstract

The study aims to find the relation between administrative leadership and administrative creativity level with youth and sport directorate employees' level, Elmsila state- Algiers, and presenting strategies which help hiring the modern concepts of administrative leadership styles which are closely linked to the administrative creativity at all directorates of youth and sport, and make / let the employees and administrative leaders know importance of administrative creativity, its styles, the most important components and their effects on the outstanding performance and competitiveness. We used the questionnaire and creativity scale as a study tool. The research sample consisted of 34 employees from all workers in youth and sport directorate, at Elmsila state, the sample was cadastral. We also used the descriptive method because it is suitable for the topic nature. The results showed that there is a relation between the three method of administration and the creativity level of youth and sports directorate's employees.

In general, the organization as they different in tasks, size and type faces many problems required from leaders and employees necessity of thinking and rethinking in old styles in current condition.

Brown and Truenger confirms that the style of

director of laboratory of adapted physical and sport activities programs, Academy of sciences and techniques of physical and sports activities, Elmsila University, Algiers

"' (souk ahras University, Algiers).

".. Master of sport organization and administration.

Master of sport organization and administration Assiut Journal For Sport Science Arts 
leadership in work environment produces many types of subordinates, the person who has a range of creativity this means natural result of his work environment's features ; where the style of leadership come first (Al-Robian Essam 2000, p31)

Starting from this point, we should find the meaning of administrative leadership and where is it? So, we can figure it in many levels related to administrative style: integrative leadership style, balanced leadership style, humanistic leadership style and weak leadership style according to administrative systems theory which consist of 4 styles: Autocratic leadership participative leadership- fair autocratic leadership consultative leadership (Hareem Hussien 2004, p37,38)

The administrative creativity considered an essential factor to cope with administrative side's changes and this requires providing an administrative environment which encourage the creativity and make it a developed modern style serve the organization and the employee especially.

The administration experts agreed on the organizations and institutions' needy of administrative creativity, it is a necessity imposed by cultural, political, social and economic variables in this changeable world.

El Hekbany confirms that the creativity is all processes which the employee conduct inside the organization, these processes distinguished with originality, fluency, flexibility, venture, ability to analyze, thinking out of the box weather for person or the organization where he work and, the sensitivity to problems which happen through dealing with surrounding environment. (AlHokbany 1418a.h. p15)

This is what supported by theory of (March \& Simon, 1958) which explained creativity through processing problems which obstruct the organizations, where some organizations face gab between what they do and what they must do. So, it tries creating substitutes through search process, the process of creativity pass along many stages; performance gab - lack 
of welfare - search, awareness and substitutes - then creativity. From here we can form the creativity idea and its effect on organization, institution, person and group; this confirmed by "Al-Sheny", he said that we can distinguish between three levels of creativity; creativity on person level, creativity on group level, and creativity on organization level (Al-Shbeny Hashem: 1997, p94)

There are many essential administrative concepts as standards help us judging administrative creativity level at sport organizations \& institutions and judge on those workers in regulation and administration field in sport, also, this is the reason which give the organization; persistence, stability, competitiveness and outstanding performance according to modern development's variables \& requirements. "Mohamed Tafesh" invited to this as following: originality, fluency, flexibility, tendency to analysis and details, the ability to solve problems, tendency to experimentation, selfconfidence, risk, self-criticism (Mohamed Tafesh 2004, p23).
The administrative leadership has a great effect on workers' performance where it pushes them to make more effort to find new methods for all tasks \& activities, thus, achieve creativity levels and hard work. A lot of current chalanges and variables require from those interest in sport movement cares about the administrative leadership level and its close association with administrative creativity at all sports institutions in our countries, if we want to adopt a philosophy include all modern concepts \& knowledge in this field to take advantage as much as possible of the employees' capabilities and abilities, invest, direct and supervising their energies through training and continuous education. Also, providing all the necessary materialist, technical and human resources to ensure high levels of achievement and performance.

As we mentioned before we got to present the general question as following:

Is there a relation between administrative leadership and administrative creativity of the employees in youth and sport directorate?

\section{1- Sub questions:}


* Is there a correlated relation of integrative leadership style with administrative creativity's level?

* Is there a correlated relation of balanced leadership style with administrative creativity's level?

* Is there a correlated relation of humanistic leadership style with administrative creativity's level?

\section{2- Study hypotheses:}

- The integrative leadership style relates with administrative creativity's level.

- The humanistic leadership style relates with administrative creativity's level.

- The balanced leadership style relates with administrative creativity's level?

3- Study Goals: Measuring the relation between integrative leadership style and administrative creativity's level.

- Measuring the relation between balanced leadership style and administrative creativity's level.

- Measuring the relation between humanistic leadership style and administrative creativity's level.
4- Study importance:

Providing strategies and programs allow hiring the modern concepts of administrative leadership' styles which closely related to the level of administrative creativity at youth and sport directorates level.

- Make the employees and directors know importance of administrative creativity

- Make the employees know styles and important elements of administrative creativity.

- Let the leader identify the creativity elements and its effects on organization in terms of stability and continuity.

5 - Keywords: administrative leadership: is social phenomenon represented in an influential person among people stand to express the feelings of group and meet their demands which they can't do by themselves. (Ibrahim Ben Shehab 1996, p246).

Procedural definition of administrative leadership: are a group of jobs and tasks carried out by the leader to run affairs of foundation and institution or organization to make sure its progress, success and its continuity in the present and future. 
Creativity: is the process which leads to appear idea or product or new service which can be adopted by those working in the organization or imposed on them by the decision makers where it resulting a sort of change in the environment or processes or the organization's outputs. (Gamal Eldeen Mohamed Ibn Makram 1990,p6)

Procedural definition of creativity: the person's ability to hire former skills to got or gains renewable skills and develops it in something he wants or others want.

\section{Earlier studies:}

1- First study: Mohamed Ben Ahmed; entitled: The leadership' styles and their relation with administrative creativity by using administrative network theory", Om Elkora University, 1423 a.h.

Study problem: what is the relation between leadership styles and administrative creativity according to administrative network theory in view-point of directors of day primary schools for boys in Jeddah?

Study goals: Identifying the relation between leadership styles and creativity in administrative network theory in primary schools at Jeddah city.

\section{Study tool and method:}

The researcher used descriptive method and survey as a tool to collect information.

\section{Study community \& sample:} the study's community consists of all primary schools' directors in Jeddah city.

Study results: the creativity levels which more sovereignty: flexibility, then fluency, next self-confidence, after that originality and adventure.

- There is significance positive correlated relationship among creativity in general and balanced leadership, social leadership, team leadership and whole leadership.

\section{2- Second study: the} researcher/ Mohamed Kareem Hosny, Title: relation of transformational leadership with administrative creativity of departments' academics heads in Islamic University, Gaza 1431a.h.

Study problem: what is the relation between transformational leadership and developing creative abilities of departments' heads?

The study aims to: identifying the relation between reality of 
acquirement/ having of academic leaders in Islamic University for characteristics and features of transformational leader and availability of creativity among departments' academics heads in Islamic University, Gaza.

- Study method: the researcher used analytic descriptive method.

- Study tool: Questionnaire, which distributed on the whole sample to collect the required data for the study.

- Study sample \& community: whole departments' academic heads and number of the questionnaire under study are 45 questionnaires.

- Study results: There is a relation between transformational leadership features and elements among academic leaders, and availability of creative abilities among departments' academic heads.

3- Third study: The researcher/ Mowafek Ahmed Shehaza: Title: The common styles of leadership among schools' directors and their relation with education quality level according to teachers' view point in Oman, 1433a.h.

- Study problem: what are the common leadership styles and what is the relation between them and education quality level in view point of teachers. - Study goals: identifying the common leadership styles and their relation with education quality level in view point of teachers.

- Study method: the researcher used correlated descriptive method as it is the most suitable method for this study.

- Study tool: the researcher used questionnaire tool to collect the information. Study sample: 500 female and male teachers.

- Study results: The school directors don't know the styles of leadership and don't trust in teacher's abilities.

4- Fourth study: the researcher/ Basam Ben Menawr Elanzy, title: the organizational culture and administrative creativity among those working in public foundations at Riyadh city, 1430a.h.

Study problem: what is the effect of organizational culture on administrative creativity in public foundations at Saudi Arabia (KSA)?

Study goals: knowing the organizational culture's effect on administrative 
creativity in public foundations at Saudi Arabia (KSA).

Study tool: the

questionnaire used as a tool to collect data, where includes the following parts:

The $1^{\text {st }}$ part: to measure the values which forms the organizational culture, this scale designed by Frances wood Cook and translated to Arabic. The scale consists of 60 items for measuring 12 values, 5 items for each value. This scale modified to suit the study's requirements to include 32 items according to the gradient pentathlon scale (Likert) for measuring 8 values by 4 items for each value. So, the scale measures the following values: strength, purity, reward, efficiency, effectiveness, honesty, work teams, organization.

The $2^{\text {nd }}$ part: to measure the elements of administrative creativity, this scaled designed by Turkey Elhakbany (1418a.h.). Where it used in this study after modifying it to measure the administrative creativity characteristics. This scale includes 21 items according to the gradient pentathlon scale (Likert) where it measures the following characteristics:-
Originality, fluency, flexibility, the ability to analyze, sensitivity to problems, thinking out of the box.

Study method: the descriptive survey method Study sample \& community: the employees of public foundations at $\mathrm{Al}$ Riyadh city.

Study results: whole values which form the organizational culture are common in public foundations at Al Riyadh city, they are: (strength, purity, efficiency, effectiveness, honesty, work teams, organization.) except reward.

6- The study's field rules:

Study method: we used the descriptive method because it is suitable for study nature.

Study sample: the all employees in youth and sport directorate at Elmsila state, the sample was survey and consisted of 34 .

Study tools: we used questionnaire and administrative creativity scale.

The administrative creativity scale: prepared by Adel Ben Saleh Elshkha 2003, it consists of 21 sentences after determining the administrative creativity concept and its different characteristics 
through what presented by Abdel-Rahman Ben Ahmed Elhaygan.

Method of correcting administrative creativity scale: the scale consists of 21 sentences, each sentence has 5 dimensions; Always, Mostly, Sometimes, Rarely, Never, the answer as following: Never = 1 , rarely $=2$, sometimes $=3$, mostly $=4$, always $=5$. These results collected in dimensions, then calculate the total degree which ranged theoretically from 1 to 2.5 (low level), from 2.5 to 3.5 (intermediate level), from 3.5 to 5 (high level)

7- Scientific conditions of study tools: external credibility: to achieve external credibility of the questionnaire which consist of administrative leadership styles, its relation with administrative creativity components and the scale to measure administrative creativity level among the employees in youth and sport directorate, this scale showed on a number of experienced professors in administration field to assess it, where they conducted some changes and removed some question to get the last formulation for this scale.

- Internal harmony: we conducted a pre study to achieve internal harmony where the questionnaire and scale distributed on random sample of employees on youth and sport directorate, consists of (5) persons from different positions, then the correlation coefficient calculated between each sentence of questionnaire and the demotions which form this sentence.

Performance stability: by using Cronbach's Alpha coefficient

Table (1)

Dimensions stability coefficient of administrative creativity and leadership styles' questionnaire

\begin{tabular}{l|l|c}
\hline \hline \multicolumn{2}{c|}{ The questionnaire } & \\
\hline \hline $\begin{array}{l}\text { Leadership styles and } \\
\text { administrative }\end{array}$ & $\begin{array}{l}\text { Integrative leadership } \\
\text { style \& administrative }\end{array}$ & 0.63 \\
\hline \hline \multicolumn{2}{|l|}{ Assiut Journal For Sport Science Arts } & \\
\end{tabular}




\begin{tabular}{l|l|c}
\hline \hline creativity & creativity level & \\
\cline { 2 - 3 } & $\begin{array}{l}\text { Humanistic leadership } \\
\text { style \& administrative } \\
\text { creativity level }\end{array}$ & 0.59 \\
\cline { 2 - 3 } & $\begin{array}{l}\text { Balanced leadership } \\
\text { style \& administrative } \\
\text { creativity level }\end{array}$ & 0.61 \\
\hline Administrative creativity level' scale & 0.56 \\
\hline \hline
\end{tabular}

Analyzing table (1): we can notices that each questionnaire's dimension which represented in; dimension of integrative leadership style\& administrative creativity level, dimension of humanistic leadership style \& administrative creativity level, and dimension of balanced leadership style \& administrative creativity levelhas high stability coefficient

\section{8- Showing \& analyzing the results:-}

and statistically significant at level (0.05), also the stability coefficient of administrative creativity level's dimension, is high and statistically significant, among those working in youth and sport directorate where stability coefficient' values range between (0.56) and (0.63). This signifies stability of the results which we can get after applying this tool in study. 
Table (2)

Answers of sample member for first question "Does the integrative leadership style relate with administrative creativity level?"

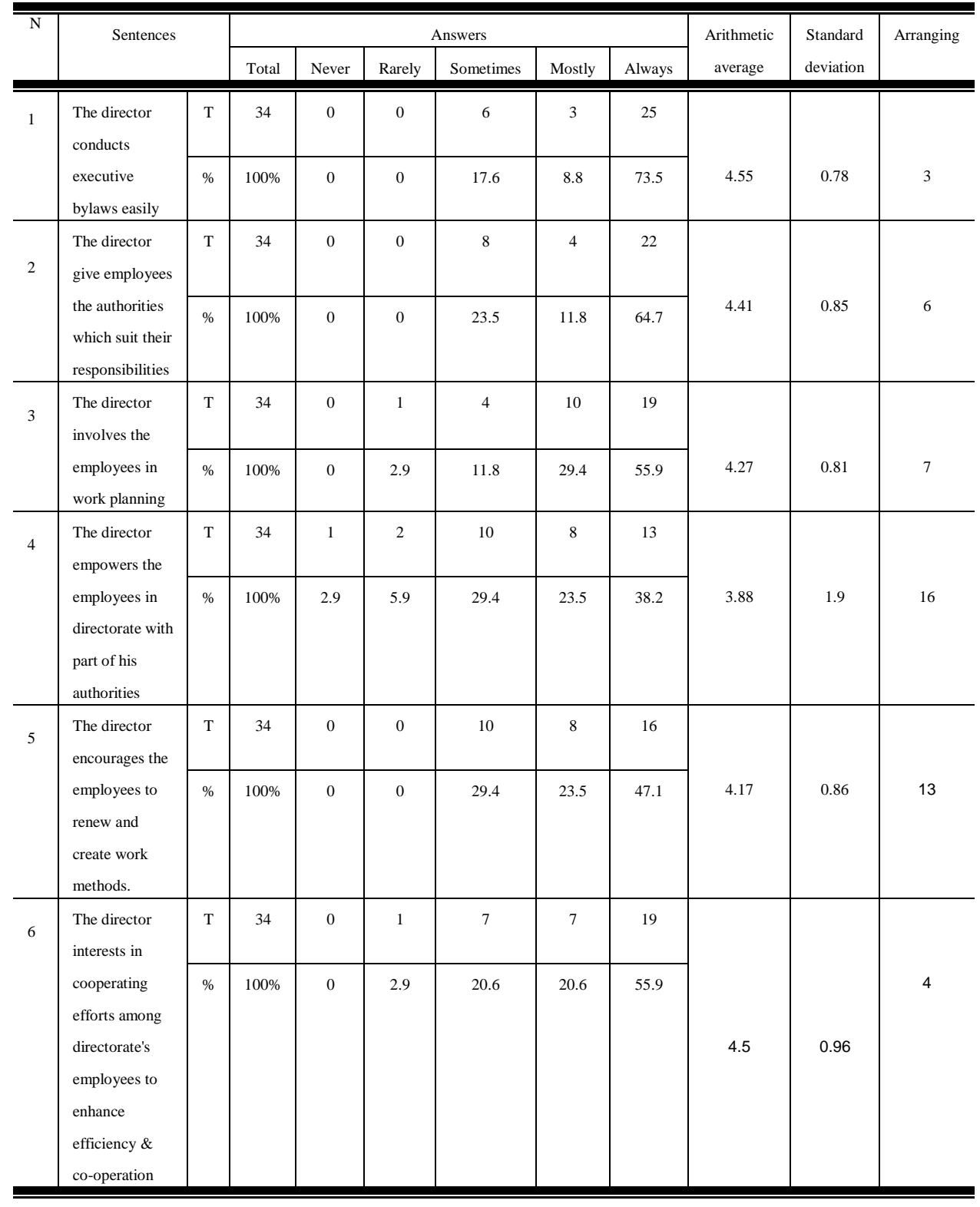

Follow Table (2)

Assiut Journal For Sport Science Arts 
Answers of sample member for first question "Does the integrative leadership style relate with administrative creativity level?"

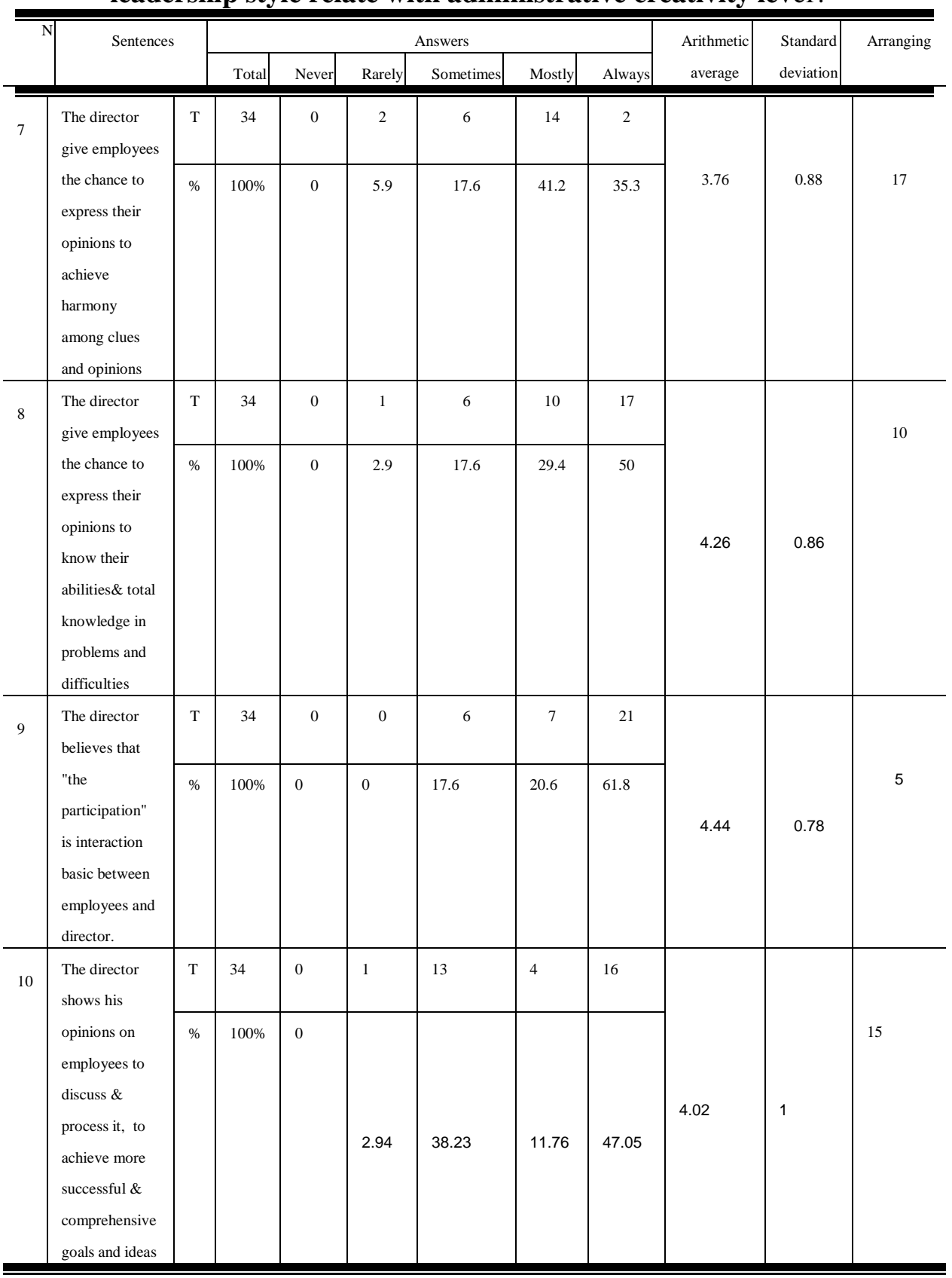


Analyzing table (2): we conclude that; the general arithmetic average value of sentences reached (4.23), while general standard deviation reached (0.88). This prove validity of $1^{\text {st }}$ hypothesis which handle relation of integrative leadership style with administrative creativity level because most results of arithmetic average are significantly close to answers degree.

\section{Table (3)}

Answers of sample member for $2^{\text {nd }}$ question" Does the humanistic leadership style relate with administrative creativity level?"

\begin{tabular}{|c|c|c|c|c|c|c|c|c|c|c|c|}
\hline \multirow[t]{2}{*}{$\overline{\mathrm{N}}$} & \multirow{2}{*}{\multicolumn{2}{|c|}{ Sentences }} & \multicolumn{6}{|c|}{ Answers } & \multirow{2}{*}{$\begin{array}{c}\text { Arithmetic } \\
\text { average }\end{array}$} & \multirow{2}{*}{$\begin{array}{l}\text { Standard } \\
\text { deviation }\end{array}$} & \multirow[t]{2}{*}{ Arranging } \\
\hline & & & Total & Never & Rarely & Sometimes & Mostly & Always & & & \\
\hline \multirow[t]{2}{*}{11} & $\begin{array}{l}\text { The director respects the } \\
\text { employees' feelings and } \\
\text { conditions during work }\end{array}$ & $\mathrm{T}$ & 34 & 0 & 0 & 10 & 7 & 17 & \multirow{2}{*}{4.2} & \multirow{2}{*}{0.88} & \multirow{2}{*}{12} \\
\hline & & $\%$ & $100 \%$ & 0 & 0 & 29.4 & 20.6 & 50 & & & \\
\hline \multirow[b]{2}{*}{12} & \multirow{2}{*}{$\begin{array}{l}\text { The director don't hesitate in } \\
\text { helping employees and solve } \\
\text { some of their problems during } \\
\text { work }\end{array}$} & $\mathrm{T}$ & 34 & 1 & 1 & 2 & 6 & 24 & \multirow[b]{2}{*}{4.5} & \multirow[b]{2}{*}{0.96} & \multirow[b]{2}{*}{4} \\
\hline & & $\%$ & $100 \%$ & 2.9 & 2.9 & 5.9 & 17.6 & 70.6 & & & \\
\hline \multirow{2}{*}{13} & \multirow{2}{*}{$\begin{array}{l}\text { The director is not slow in } \\
\text { punching the employees those } \\
\text { do badly to organization and } \\
\text { institution }\end{array}$} & $\mathrm{T}$ & 34 & 0 & 2 & 6 & 6 & 20 & \multirow[b]{2}{*}{4.29} & \multirow[b]{2}{*}{0.97} & \multirow[b]{2}{*}{9} \\
\hline & & $\%$ & $100 \%$ & 0 & 5.9 & 17.6 & 17.6 & 58.8 & & & \\
\hline \multirow{3}{*}{14} & \multirow{3}{*}{$\begin{array}{l}\text { The director seeks to } \\
\text { organization fame through } \\
\text { observing employees' } \\
\text { behaviors with directorate }\end{array}$} & $\mathrm{T}$ & 34 & 0 & 0 & 3 & 5 & 26 & \multirow[t]{3}{*}{4.76} & \multirow[t]{3}{*}{0.63} & \multirow{3}{*}{8} \\
\hline & & & & & & & & & & & \\
\hline & & $\%$ & $100 \%$ & 0 & 0 & 8.8 & 14.7 & 67.5 & & & \\
\hline \multirow[t]{2}{*}{15} & \multirow{2}{*}{$\begin{array}{l}\text { The director respect work time } \\
\text { and appointments of his } \\
\text { position }\end{array}$} & $\mathrm{T}$ & 34 & 0 & 0 & 10 & 1 & 23 & \multirow[b]{2}{*}{4.38} & \multirow[b]{2}{*}{0.92} & \\
\hline & & $\%$ & $100 \%$ & 0 & 0 & 29.4 & 2.9 & 67.6 & & & 7 \\
\hline \multirow[t]{2}{*}{16} & \multirow{2}{*}{$\begin{array}{l}\text { The director insists on } \\
\text { attending and leaving of } \\
\text { employees in specific times. }\end{array}$} & $\mathrm{T}$ & 34 & 0 & 0 & 0 & 5 & 29 & \multirow[b]{2}{*}{4.85} & & \\
\hline & & $\%$ & $100 \%$ & 0 & 0 & 0 & 14.7 & 85.3 & & 0.35 & 1 \\
\hline & The director applies & $\mathrm{T}$ & 34 & 2 & 5 & 9 & 8 & 10 & 4.14 & 1.23 & \\
\hline & $\begin{array}{l}\text { programs to motivate the } \\
\text { employees. }\end{array}$ & $\%$ & $100 \%$ & 5.9 & 14.7 & 26.5 & 23.5 & 29.4 & & & 14 \\
\hline 18 & $\begin{array}{l}\text { The director conducts } \\
\text { meetings with the employees } \\
\text { to study the new in work to }\end{array}$ & $\mathrm{T}$ & 34 & 5 & 2 & 11 & 3 & 13 & & & 18 \\
\hline & improve service. & $\%$ & $100 \%$ & 14.7 & 5.9 & 32.4 & 8.8 & 38.2 & 3.5 & 1.07 & \\
\hline & The director is mild toward the & $\mathrm{T}$ & 34 & 1 & 1 & 7 & 5 & 20 & & & \\
\hline & & $\%$ & $100 \%$ & 2.9 & 2.9 & 20.6 & 14.7 & 58.8 & 4.23 & 0.78 & 11 \\
\hline 20 & The director doesn't hesitate to & $\mathrm{T}$ & 34 & 0 & 1 & 6 & 8 & 19 & & & \\
\hline & employees during work & $\%$ & $100 \%$ & 0 & 2.94 & 17.6 & 23.5 & 55.9 & 4.32 & 0.76 & 8 \\
\hline
\end{tabular}

Analyzing table (3): we conclude that; the general arithmetic average value of sentences reached (4.30), while general standard deviation reached (0.86). This prove

Assiut Journal For Sport Science Arts 
validity of $2^{\text {nd }}$ hypothesis which handle relation of humanistic leadership style with administrative creativity level because most results of arithmetic average are significantly close to answers degree (mostly \& always).

\section{Table (4)}

Answers of sample member for $3^{\text {rd }}$ question" Does the balanced leadership style relate with administrative creativity level?"

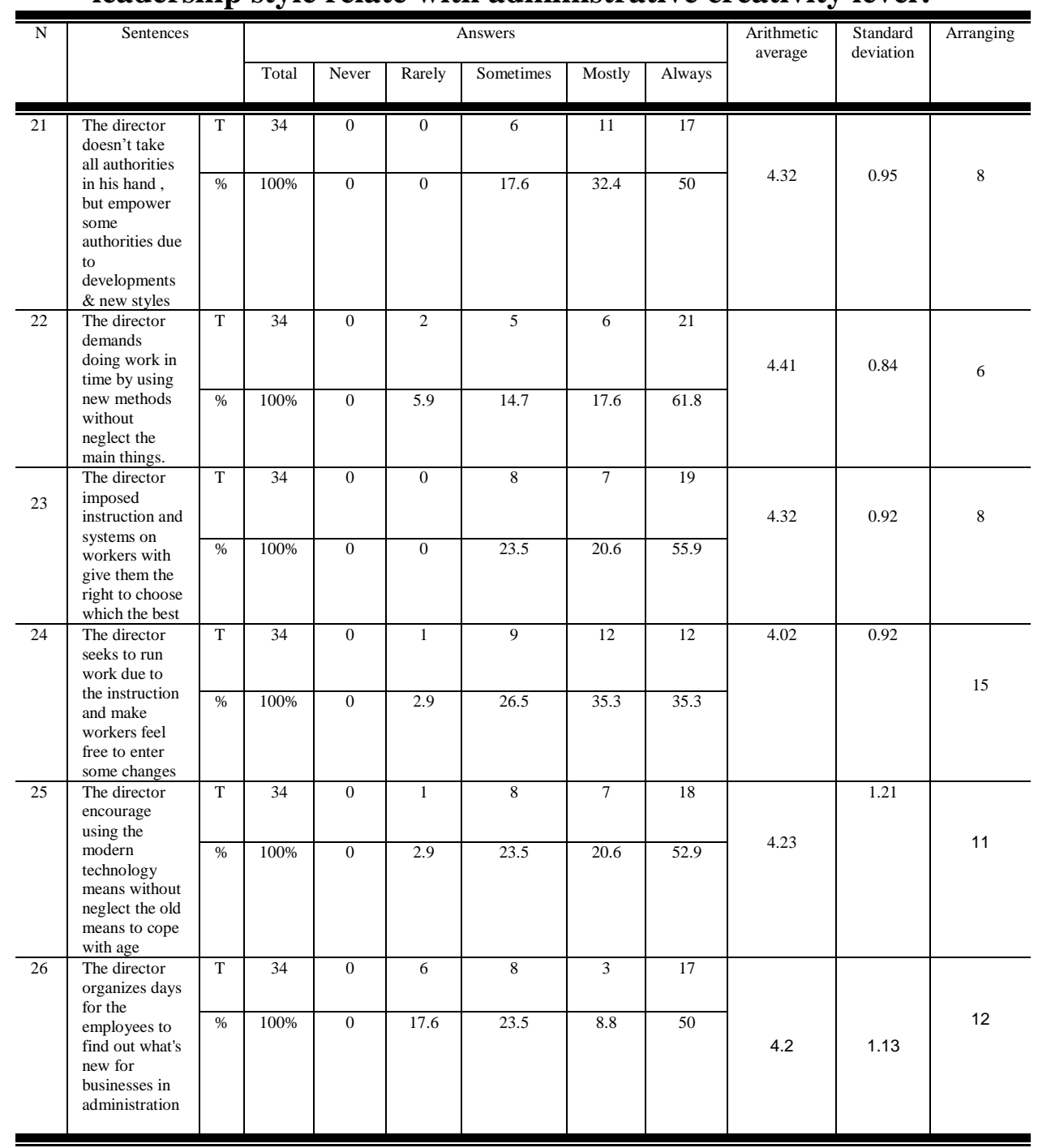


Follow Table (4)

Answers of sample member for $3^{\text {rd }}$ question" Does the balanced leadership style relate with administrative creativity level?"

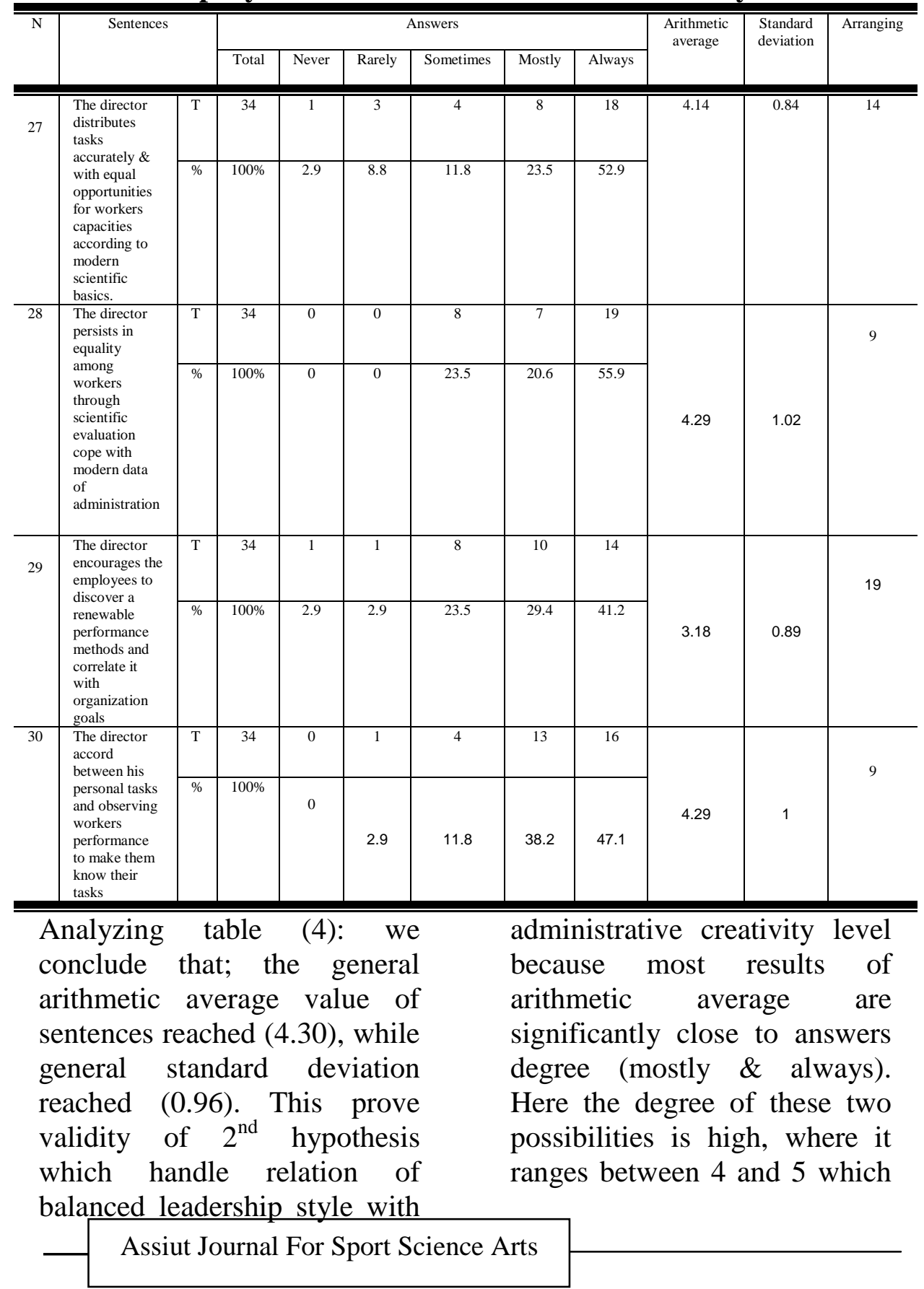


mean a high degree of agreement.

General conclusions:

- With regard to $1^{\text {st }}$ hypothesis which handles integrative leadership style and its relation with administrative creativity level. Here the relationship formed by obtained results, regard to arithmetic average which reached (4.23). This confirms that there is a strong positive direct relation between integrative leadership style and administrative creativity level; when the leadership style was integrative the administrative creativity level is excellent.

- With regard to $2^{\text {nd }}$ hypothesis which handle humanistic leadership style and its relation with administrative creativity level, we find that there is a big relationship between them, and this what the correlation coefficient (Person) explained, with administrative creativity level where the correlation coefficient reached (0.577) and this show intermediate positive direct relation. This means whenever the leadership style is humanistic whenever the administrative creativity level increase among employees.

- regard to $3^{\text {rd }}$ hypothesis which handles balanced leadership style and its relation with administrative creativity level, we find that there is a big relation between them; this is what the question's arithmetic average shows where it reached (4.30). This has big significance on existence of relationship. Also what proved by the correlation coefficient Person where reached (0.847). This proves that there is strong positive direct relation between them. Whenever the leadership style is balanced whenever administrative creativity level is excellent. This point agrees with organizational balance theory (Bernard) which says that remaining of administrative regulation and its continuance for a long time requires two things; efficiency and effectiveness.

The regulation' efficiency and dynamic lies in the desire of its members to contribute by their efforts in regulation activity, their desires need believe in achieving the goal. This signifies existence of relation among the 3 styles of leadership (integrative, humanistic, and balanced) and creativity level among those working in youth and sport directorate.

\section{References:}


1- Ibrahem Ben Shehab, Glossary of public Administration terms, Resalah Publishers, Edition 1, 1996.

2- Mahmoud Tafesh, The administrative creativity in educational supervision and school administration, Dar AlFurqan for Publishing \& Distribution, Amman 2004.

3- Gamal Eldeen Mohamed Ben Makrm Ben Manzor, Lessan al Arab, Volume 8, Dar Sader for Publishing \& Distribution, Bayrot, 1990.

4- Harem Hussien, The organizational behavior, Dar Al Hamed, Amman, 2004

5- Abdel-Kareem Bou Hafs, the applied statistics in social sciences, University publications office, edition 2, Algeria, 2006

6- Owny Moaeen Shahen et el., A study in educational and socio-psychological

foundations of humanistic creativity's phenomenon, Dar Al-Shorok for Publishing \& Distribution, Amman, 2009.

7- Al-Shebeny Hashem, Essential nature, elements and measurement methods of creativity, The administrative development magazine, issue 75, 1997, Cairo.

8- El-Robian Essam et el, Measuring the directors" perception for loyalty and creativity in public work at Kuwait, Arab Journal of Administrative sciences, edition1, Kuwait, 2000

\section{9- Mohamed Karem Hosny,} The relation of transformational leadership with administrative creativity among departments' academics' heads in Islamic University at Gaza, a thesis presented as complementary requirement to get Master degree in Human Resources Management, 2010.

10- El-Hekbany Turkey Abdel-Rahman, The effect of organizational variables on administrative creativity, A scoping study on those working in government agencies at Al-Riyadh, Unpublished Master Thesis, Al-Riyadh, King Saud University, 1418a.h.

11- Mohamed Ben Ahmed Ben Mohamed, The styles of leadership and its relation with administrative creativity by using administrative network theory, A complementary requirement to get Master degree in Planning and Educational administrative, Faculty of education, UMM Al-QURA UNIVERSITY, Mecca, 1423a.h. 
12- Mofek Ahmed Shehaza, The common styles of leadership among private schools' directors and its relation with education quality's level according to teachers' opinions, Amman, A complementary requirement to get Master degree in Administration and Educational leadership, Faculty of educational sciences, Middle East University, 2012

\section{3- Bassam Ben Menwar El-} Anzy, Organizational culture and Administrative creativity among those working in public organizations, Al-Riyadh, A complementary requirement to get Master degree in Public Administration Department. . 